ARTICLE

Received 2 Jul 2013 | Accepted 28 Oct 2013 | Published 20 Nov $2013 \quad$ DOl: 10.1038/ncomms3826

\title{
A light-induced spin crossover actuated single-chain magnet
}

Tao Liu', Hui Zheng' ${ }^{1}$ Soonchul Kang${ }^{2}$, Yoshihito Shiota ${ }^{3}$, Shinya Hayami ${ }^{4}$, Masaki Mito ${ }^{5}$, Osamu Sato ${ }^{2}$, Kazunari Yoshizawa ${ }^{3}$, Shinji Kanegawa ${ }^{2} \&$ Chunying Duan ${ }^{1}$

Both spin-crossover complexes and molecular nanomagnets display bistable magnetic states, potentially behaving as elementary binary units for information storage. It is a challenge to introduce spin-crossover units into molecular nanomagnets to switch the bistable state of the nanomagnets through external stimuli-tuned spin crossover. Here we report an iron(II) spincrossover unit and paramagnetic iron(III) ions that are incorporated into a well-isolated double-zigzag chain. The chain exhibits thermally induced reversible spin-crossover and lightinduced excited spin-state trapping at the iron(II) sites. Single-chain magnet behaviour is actuated accompanying the synergy between light-induced excited spin-state trapping at the iron(II) sites and ferromagnetic interactions between the photoinduced high-spin iron(II) and low-spin iron(III) ions in the chain. The result provides a strategy to switch the bistable state of molecular nanomagnets using external stimuli such as light and heat, with the potential to erase and write information at a molecular level.

\footnotetext{
${ }^{1}$ State Key Laboratory of Fine Chemicals, Dalian University of Technology, 2 Linggong Road, Dalian 116024, China. ${ }^{2}$ Institute for Materials Chemistry and Engineering, Kyushu University, 6-1 Kasuga-koen, Kasuga 816-8580, Japan. ${ }^{3}$ Institute for Materials Chemistry and Engineering, Kyushu University, Nishi-ku 819-0395, Japan. ${ }^{4}$ Graduate School of Science and Technology, Kumamoto University, 2-39-1 Kurokami, Kumamoto 860-8555, Japan. ${ }^{5}$ Faculty of Engineering, Kyushu Institute of Technology, Kitakyushu 804-8550, Japan. Correspondence and requests for materials should be addressed to T.L. (email: liutao@dlut.edu.cn).
} 
$t$ is a challenge to reduce the size of electronic devices and increase information density in materials area. As a result, molecules possessing magnetic bistable states are attracting a great deal of attention ${ }^{1-18}$, because these bistable states can act as elementary binary units (bits) used for information storage, providing potential applications in high-density information storage $^{3,5}$, quantum computing ${ }^{10}$ and spintronics ${ }^{13}$. In general, spin-crossover (SCO) complexes $^{1-7}$ and molecular nanomagnets ${ }^{8-18}$ show such magnetic bistable states. SCO complexes show reversible transformation between a high-spin (HS) and a low-spin (LS) state $^{1-7}$. In particular, the light-induced excited spin-state trapping $(\text { LIESST })^{19-34}$, which induces conversion of a LS state to a HS state by means of light irradiation, has attracted considerable interest. LIESST effects have been observed in various $\mathrm{Fe}^{\mathrm{II}}$ (or a few $\mathrm{Fe}^{\mathrm{III}}$ ) mononuclear complexes ${ }^{19-24}$. Moreover, SCO units and other paramagnetic ions have been linked via a short bridge to control intramolecular magnetic interactions ${ }^{25-33}$ and generate magnetic ordering $^{34}$ via LIESST. However, no one has so far succeeded in introducing light-responsive SCO units into molecular nanomagnets, such as single-chain magnets (SCMs) and singlemolecule magnets, to switch the bistable states of the nanomagnets.

SCMs possess bistable states capable of interchanging between two magnetic polarization directions ${ }^{14-18}$. Although various types of SCMs have been synthesized, it is a challenge to produce and eliminate their bistable states using external stimuli, such as light, heat and so on ${ }^{35-37}$. The requirements for obtaining an SCM are uniaxial (Ising) anisotropy, strong intrachain magnetic interactions and weak interchain magnetic interactions ${ }^{14-18}$. Hence, the most effective approach towards tuning the SCM behaviour is to control directly the anisotropy of ions and intrachain magnetic interactions using external stimuli. LIESST can involve concomitant changes of spin state and anisotropy at the metal centres and subsequent changes of magnetic interaction pathways in the framework ${ }^{19-34}$. If the light-responsive SCO units can be incorporated in a chain, both the anisotropy of metal ions and the intrachain magnetic interactions will be tuned accompanying the LIESST effect ${ }^{25-34}$, producing a potential lightresponsive SCM. Moreover, LIESST involves only one type of metal ion, providing the possibility to combine SCO units and various metal ions to produce photoswitchable SCMs. However, the LIESST effect has not yet been adopted successfully to switch the SCM behaviour.

To synthesize a photoswitchable SCM using LIESST effect, the requirements of both SCM behaviours and LIESST effect should be considered. Until now, LIESST effects have been reported for $\mathrm{Fe}^{\mathrm{II}}$ and $\mathrm{Fe}^{\mathrm{III}}$ complexes ${ }^{19-34}$. Moreover, SCM behaviours have also been reported for complexes containing $\mathrm{HS} \mathrm{Fe}^{\mathrm{II}}$ and $\mathrm{LS} \mathrm{Fe}^{\mathrm{III}}$ ions $^{38}$. Therefore, it is possible to obtain a photoswitchable SCM based on the LIESST effect of $\mathrm{Fe}^{\mathrm{II}}$. Herein, we incorporate $\mathrm{Fe}^{\mathrm{II}}$ SCO units and paramagnetic LS Fe $\mathrm{III}^{\mathrm{II}}$ ions into a cyanide-bridged $\left\{\mathrm{Fe}^{\mathrm{III}}{ }_{2} \mathrm{Fe}^{\mathrm{II}}\right\}$ chain using the following building block: $\left[\mathrm{Bu}_{4} \mathrm{~N}\right]\left[\mathrm{Fe}\left(\mathrm{Tp}^{*}\right)(\mathrm{CN})_{3}\right] \quad\left(\mathrm{Tp}^{*}=\right.$ hydrotris(3,5-dimethylpyrazolyl) borate). The cyanide bridges are supposed to link $\mathrm{Fe}^{\mathrm{II}}$ and $\mathrm{Fe}^{\mathrm{III}}$ ions into a chain and provide efficient superexchange pathways for strong magnetic interactions. The $\mathrm{HS} \mathrm{Fe}^{\mathrm{II}}$ ion is paramagnetic $(\mathrm{S}=2)$ and usually has a strong anisotropy, whereas the LS Fe ${ }^{\mathrm{II}}$ ion is diamagnetic $(\mathrm{S}=0)$ and has no anisotropy, providing a switchable anisotropy. Moreover, the intrachain magnetic interactions between $\mathrm{Fe}^{\mathrm{III}}$ and $\mathrm{Fe}^{\mathrm{II}}$ ions can be switched accompanying the diamagnetic and paramagnetic transformations at the $\mathrm{Fe}^{\mathrm{II}}$ sites. The bulky $\mathrm{Tp}^{*}$ ligand is introduced to avoid interchain magnetic interactions. Furthermore, a long ditopic, magnetically inert organic linker N,N'-bis-pyridin-4ylmethylene hydrazine (bpmh) is adopted to tune the ligand field of $\mathrm{Fe}^{\mathrm{II}}$ sites, to provide the possible light-induced spin transition and to link the Ising chains into two-dimensional networks, maintaining a sufficiently large ratio of intra- to interchain magnetic interactions without changing the SCM behaviour significantly. Herein, based on the above strategy, the complex $\left\{\left[\mathrm{Fe}^{\mathrm{III}}\left(\mathrm{Tp}^{*}\right)(\mathrm{CN})_{3}\right]_{2} \mathrm{Fe}^{\mathrm{II}}(\mathrm{bpmh})\right\} \cdot 2 \mathrm{H}_{2} \mathrm{O}(\mathbf{1})$, composed of cyanidebridged $\left\{\mathrm{Fe}^{\mathrm{III}}{ }_{2} \mathrm{Fe}^{\mathrm{II}}\right\}$ chains, is synthesized. Complex 1 exhibits thermally induced reversible SCO and photoinduced spin transition at the $\mathrm{Fe}^{\mathrm{II}}$ sites. The SCM behaviour is switched, accompanying the synergy between the LIESST effect at the Fe $\mathrm{II}^{\mathrm{II}}$ sites, and the ferromagnetic interactions between the photoinduced $\mathrm{HS} \mathrm{Fe}^{\mathrm{II}}$ and $\mathrm{LS} \mathrm{Fe} \mathrm{FII}^{\mathrm{III}}$ ions in the chain.

\section{Results}

Structural characterization. A crystal of the target compound was synthesized through reaction of complexes $\left[\mathrm{Bu}_{4} \mathrm{~N}\right][-$ $\left.\mathrm{Fe}\left(\mathrm{Tp}^{*}\right)(\mathrm{CN})_{3}\right]$, bpmh and $\mathrm{Fe}\left(\mathrm{ClO}_{4}\right)_{2} \cdot 6 \mathrm{H}_{2} \mathrm{O}$ in a methanol/water mixture placed in a test tube, using a diffusion method. Singlecrystal X-ray diffraction analysis revealed that compound 1 crystallizes in a $C_{2 / m}$ space group (Supplementary Table S1 and Supplementary Data 1 and 2). The crystal structure comprised layers of neutral mixed valence $\left[\mathrm{Fe}^{\mathrm{III}}\left(\mathrm{Tp}^{*}\right)(\mathrm{CN})_{3}\right]_{2} \mathrm{Fe}^{\mathrm{II}}(\mathrm{bpmh})$ and uncoordinated water molecules between them (Fig. 1 and Supplementary Fig. S1). The layers were arranged in the $a b$ plane and stacked along the $c$ axis, and contained cyanide-bridged $\left\{\mathrm{Fe}^{\mathrm{III}}{ }_{2} \mathrm{Fe}^{\mathrm{II}}\right\}$ double-zigzag chains running parallel to the crystallographic $a$ axis (Fig. 1a). The $\mathrm{Fe}^{\mathrm{III}}{ }_{2} \mathrm{Fe}_{2}{ }_{2}$ square units exhibited two orientations of their mean planes, with a dihedral angle (hereafter denoted as $\phi$ ) between them. The chains were further
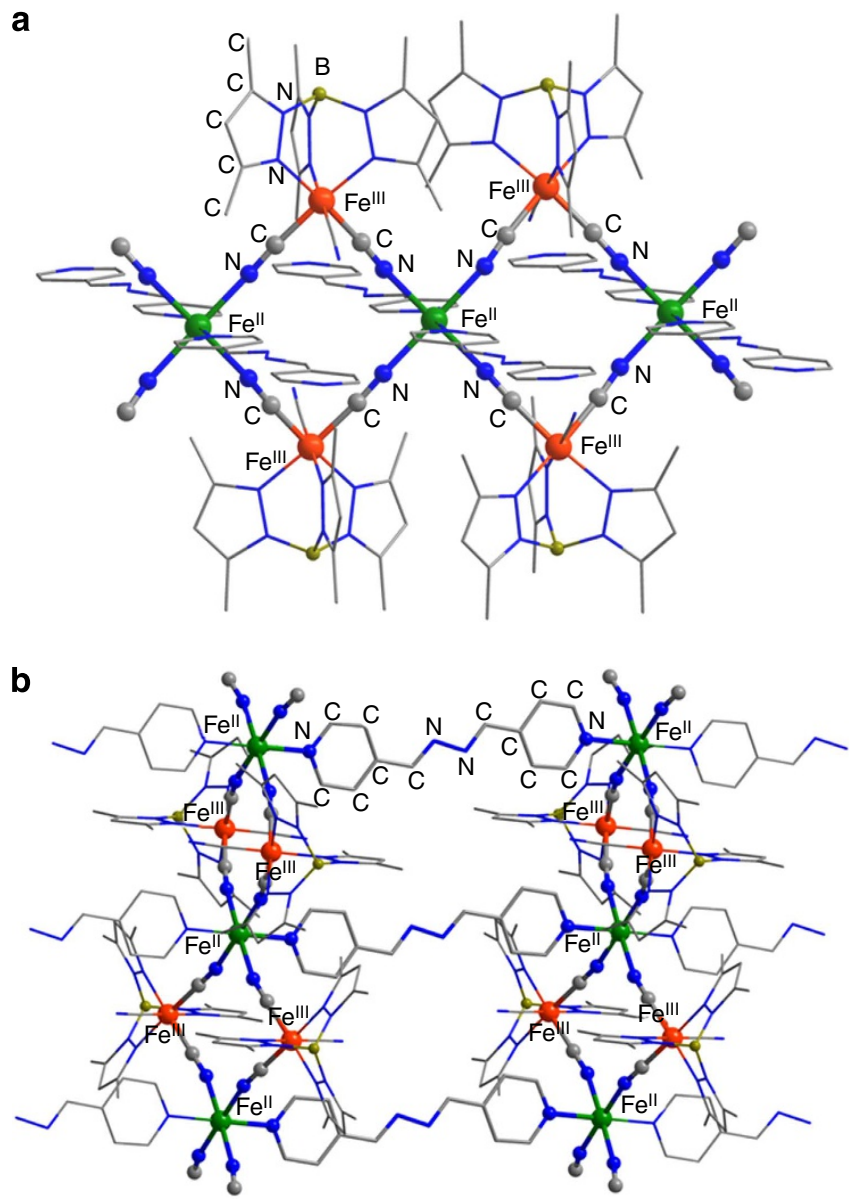

Figure 1 | Crystal structure of compound 1. The green, orange, grey, blue and dark yellow spheres represent $\mathrm{Fe}^{\mathrm{II}}, \mathrm{Fe}^{\mathrm{III}}, \mathrm{C}, \mathrm{N}$ and B atoms, respectively. Hydrogen atoms and solvent molecules have been omitted for clarity.

(a) Structure of the chains. (b) Structure of the layers. 
linked by bis-monodentate bpmh ligands along the apical direction of the $\mathrm{Fe}^{\mathrm{II}}$ centres to a layer framework (Fig. 1b). The shortest interchain metal-metal distance was $10.69 \AA$. Such a large distance will minimize interchain magnetic interactions, providing the potential for an SCM behaviour without magnetic ordering. Within the neutral chain, each $\left[\mathrm{Fe}^{\mathrm{III}} \mathrm{Tp}^{\star}(\mathrm{CN})_{3}\right]^{-}$entity linked two $\mathrm{Fe}^{\mathrm{II}}$ ions through two of its three cyanide groups in the cis positions, and each $\mathrm{Fe}^{\mathrm{II}}$ ion linked four $\left[\mathrm{Fe}^{\mathrm{III}} \mathrm{Tp}^{*}(\mathrm{CN})_{3}\right]^{-}$ entities via coordination to cyanide nitrogen atoms, forming mixed-valence double-zigzag chains. The crystal structure contained one unique $\mathrm{Fe}^{\mathrm{III}}$ and one unique $\mathrm{Fe}^{\mathrm{II}}$ centre. The $\mathrm{Fe}^{\mathrm{III}}$ centre was coordinated to three nitrogen atoms from $\mathrm{Tp}^{*}$ and three cyanide carbon atoms, and the $\mathrm{Fe}^{\mathrm{fl}}$ centre was located in the elongated $\mathrm{N}_{6}$ octahedral environment with four nitrogen atoms from $\mathrm{CN}^{-}$bridges and two nitrogen atoms from bpmh ligands. At $296 \mathrm{~K}$ (Supplementary Table S2), the $\mathrm{Fe}^{\mathrm{II}}-\mathrm{N}_{\text {cyanide }}$ and $\mathrm{Fe}^{\mathrm{II}}-\mathrm{N}_{\text {bpmh }}$ distances were $2.158-2.162$ and $2.179 \AA$, respectively, whereas the $\mathrm{Fe}^{\mathrm{III}}-\mathrm{C}$ and $\mathrm{Fe}^{\mathrm{III}}-\mathrm{N}$ bond distances were $1.893-1.926$ and 1.976-2.020 $\AA$, respectively. A comparison of these bond lengths with the reported examples suggested the $\mathrm{Fe}^{\mathrm{II}}$ centres to be $\mathrm{Fe}^{\mathrm{II}}$ HS, whereas the $\mathrm{Fe}^{\mathrm{III}}$ centre to be $\mathrm{Fe}^{\mathrm{III}}{ }_{\mathrm{LS}}$, forming $\mathrm{Fe}^{\mathrm{III}}{ }_{\mathrm{LS}}$ $(\mu-\mathrm{CN}) \mathrm{Fe}_{\mathrm{HS}}^{\mathrm{II}}$ linkages ${ }^{19-36}$. The value of $\phi$ was $24.5^{\circ}$.

However, when crystals of compound $\mathbf{1}$ were cooled gradually to $13 \mathrm{~K}$ (Supplementary Table S3), the $\mathrm{Fe}^{\mathrm{II}}-\mathrm{N}$ bond distances were shortened by $\sim 0.20 \AA$. At $13 \mathrm{~K}$, the $\mathrm{Fe}^{\mathrm{II}}-\mathrm{N}_{\text {cyanide }}$ and $\mathrm{Fe}^{\mathrm{II}}-\mathrm{N}_{\mathrm{bpmh}}$ distances decreased to $1.965-1.971 \AA$ and $1.989 \AA$, respectively, which are characteristic of the $\mathrm{LS} \mathrm{Fe}^{\mathrm{II}}$ ions ${ }^{19-36}$. The $\mathrm{Fe}^{\mathrm{III}}-\mathrm{C}$ bond distances were $1.932-1.946 \AA$ and the $\mathrm{Fe}^{\mathrm{III}}-\mathrm{N}$ bonds distances were $1.987-2.020 \AA$, being nearly the same as those at $296 \mathrm{~K}$. The value of $\phi$ was $22.8^{\circ}$. These temperaturedependent structural variations suggested that $\mathrm{Fe}_{\mathrm{HS}}^{\mathrm{II}}$ transformed to $\mathrm{Fe}^{\mathrm{II}}{ }_{\mathrm{LS}}$ on cooling.

Mössbauer spectra analysis. The ${ }^{57} \mathrm{Fe}$ Mössbauer spectra were recorded at 300 and $5.0 \mathrm{~K}$ to characterize the electronic states of the Fe centres in compound $\mathbf{1}$, to confirm the Fe $\mathrm{el}^{\mathrm{II}} \mathrm{SCO}$ (Fig. 2). In the high-temperature phase at $300 \mathrm{~K}$, one quadruple doublet was observed with Mössbauer parameters of $\delta$ (isomer shift) $=$ $0.04 \mathrm{~mm} \mathrm{~s}^{-1}$ and $\Delta E_{\mathrm{Q}}$ (quadruple splitting) $=1.17 \mathrm{~mm} \mathrm{~s}^{-1}$, which are characteristic of the $\mathrm{LS} \mathrm{Fe} \mathrm{FII}^{\mathrm{III}}$ species. Another quadruple doublet with a wide $\delta=0.60 \mathrm{~mm} \mathrm{~s}^{-1}$ and $\Delta E_{\mathrm{Q}}=1.66 \mathrm{~mm} \mathrm{~s}^{-1}$ showed the typical HS state of the $\mathrm{Fe}^{\mathrm{II}}$ species. The peak area ratio of the $\mathrm{Fe}_{\mathrm{HS}}^{\mathrm{II}}$ to $\mathrm{Fe}^{\mathrm{III}}{ }_{\mathrm{LS}}$ species was $0.34 / 0.66$, consistent with the results of the single-crystal analysis. When the temperature was cooled to $5.0 \mathrm{~K}$, the quadruple doublet of $\mathrm{Fe}^{\mathrm{IIII}}$, with $\delta=0.14$ and $\Delta E_{\mathrm{Q}}=1.12 \mathrm{~mm} \mathrm{~s}^{-1}$, remained nearly unchanged, whereas that of the $\mathrm{Fe}^{\mathrm{II}}{ }_{\text {HS }}$ species disappeared. Moreover, an additional doublet with $\delta=0.49$ and $\Delta E_{\mathrm{Q}}=0.15 \mathrm{~mm} \mathrm{~s}^{-1}$, corresponding to the $\mathrm{Fe}^{\mathrm{II}}{ }_{\mathrm{LS}}$ species, was observed. The peak area ratio of the $\mathrm{Fe}^{\mathrm{II}}{ }_{\mathrm{LS}}$ to the $\mathrm{Fe}^{\mathrm{III}}$ LS species was $1: 2$ at $5.0 \mathrm{~K}$, suggesting that all $\mathrm{Fe}^{\mathrm{II}}{ }_{\mathrm{HS}}$ species transformed to $\mathrm{Fe}^{\mathrm{II}}{ }_{\mathrm{LS}}$ species during the transition from the high-temperature to the low-temperature phase.

Magnetic characterization. Temperature dependence of the magnetic susceptibility $(\chi)$ of polycrystalline samples of compound 1 was measured between 1.8 and $300 \mathrm{~K}$ to better understand the spin transition. The $\chi \mathrm{T}$ plot of the compound in cooling and heating modes under a magnetic field of 1,000 Oe is shown in Fig. 3 a. At $300 \mathrm{~K}$, the $\chi$ T product was $4.75 \mathrm{~cm}^{3} \mathrm{~mol}^{-1} \mathrm{~K}$, being typical for isolated metal ions of two LS Fe ${ }^{\mathrm{III}}(S=1 / 2)$ and one $\mathrm{HS} \mathrm{Fe}^{\mathrm{II}}(S=2)$ in an octahedral coordination environment ${ }^{38}$. It was roughly constant down to $200 \mathrm{~K}$. Lowering the temperature further, the $\chi \mathrm{T}$ product decreased steeply from $4.75 \mathrm{~cm}^{3} \mathrm{~mol}^{-1} \mathrm{~K}$ at $200 \mathrm{~K}$ to $1.21 \mathrm{~cm}^{3} \mathrm{~mol}^{-1} \mathrm{~K}$ at $70 \mathrm{~K}$, with an $S$-shaped curve being observed for SCO systems. On heating, the $\chi \mathrm{T}$ value
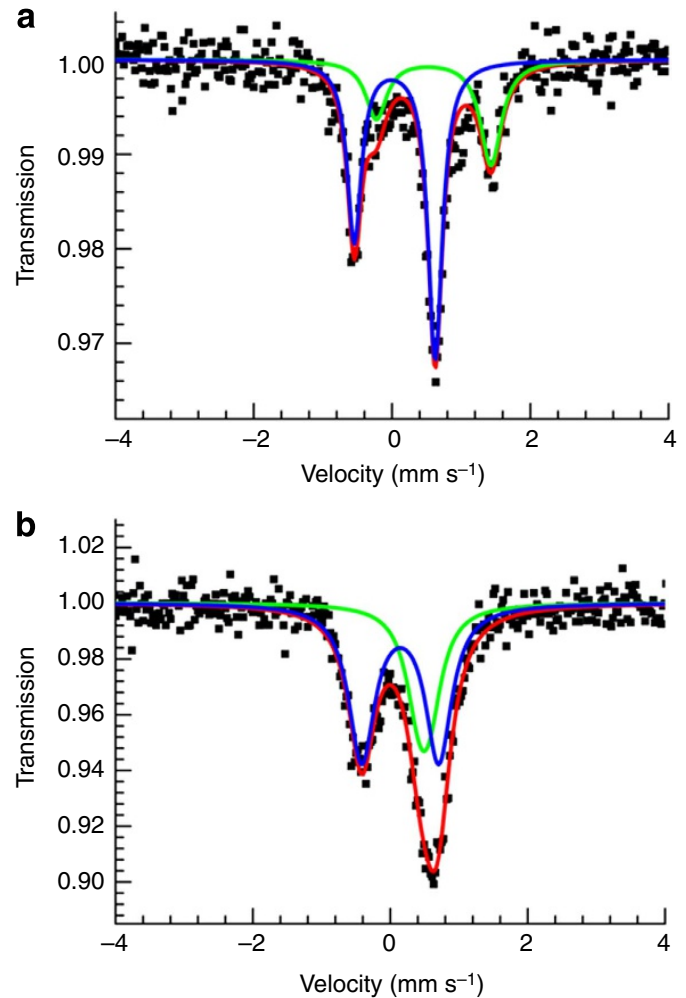

Figure 2 | Mössbauer spectra of compound 1. The solid lines represent Lorentzian curves plotted based on calculated values. (a) ${ }^{57} \mathrm{Fe}$ Mössbauer spectrum of compound $\mathbf{1}$ at $300 \mathrm{~K}$. Mössbauer parameters: $\delta$ (isomer shift) $=0.04 \mathrm{~mm} \mathrm{~s}^{-1}$ and $\Delta E_{\mathrm{Q}}$ (quadruple splitting) $=1.17 \mathrm{~mm} \mathrm{~s}^{-1}$, corresponding to the LS Fe ${ }^{I I I} ; \delta=0.60 \mathrm{~mm} \mathrm{~s}^{-1}$ and $\Delta E_{\mathrm{Q}}=1.66 \mathrm{~mm} \mathrm{~s}^{-1}$, corresponding to the $\mathrm{HS} \mathrm{Fe}{ }^{11}$. (b) ${ }^{57} \mathrm{Fe}$ Mössbauer spectrum of compound 1 at $5.0 \mathrm{~K}$. Mössbauer parameters; $\delta=0.14 \mathrm{~mm} \mathrm{~s}^{-1}$ and $\Delta E_{\mathrm{Q}}=1.12 \mathrm{~mm} \mathrm{~s}^{-1}$, corresponding to the LS Fe $\mathrm{III}^{\mathrm{III}} \delta=0.49 \mathrm{~mm} \mathrm{~s}^{-1}$ and $\Delta E_{\mathrm{Q}}=0.15 \mathrm{~mm} \mathrm{~s}^{-1}$, corresponding to the LS Fell.

increased and returned to the initial value, without thermal hysteresis. The $\chi \mathrm{T}$ product of $1.21 \mathrm{~cm}^{3} \mathrm{~mol}^{-1} \mathrm{~K}$ corresponds to two isolated $\mathrm{Fe} \mathrm{III}_{\mathrm{LS}}$ ions, suggesting that the $\mathrm{Fe}_{\mathrm{HS}}^{\mathrm{II}}$ ions were converted to the $\mathrm{Fe}^{\mathrm{II}}$ LS ions completely. Such results confirm a reversible SCO between the high-temperature phase with two $\mathrm{Fe}^{\mathrm{III}} \mathrm{LS}(S=1 / 2)$ and one $\mathrm{Fe}^{\mathrm{II}} \mathrm{HS}(S=2)$ metal ions and the lowtemperature phase with two $\mathrm{Fe}^{\mathrm{III}} \mathrm{LS}(S=1 / 2)$ and one $\mathrm{Fe}^{\mathrm{II}}{ }_{\mathrm{LS}}$ $(S=0)$ centres. The field-dependent magnetization at $1.8 \mathrm{~K}$ increased slowly to $1.95 \mathrm{~N} \beta$ at $50 \mathrm{kOe}$ (Fig. 3b), indicating paramagnetic behaviours of the two isolated $\mathrm{Fe}_{\mathrm{LS}}^{\mathrm{III}}$ ions. Alternating current (ac) magnetic susceptibility was studied as a function of both temperature and frequency. No peaks and frequency dependence were observed for both in-phase $\left(\chi^{\prime}\right)$ and out-of-phase $\left(\chi^{\prime \prime}\right)$ components (Supplementary Fig. S2), which agrees with the paramagnetic behaviour of the low-temperature phase.

Photomagnetic characterization. On light irradiation $(473 \mathrm{~nm})$ at $5 \mathrm{~K}$, a significant increase in the $\chi \mathrm{T}$ values was observed because of the photoinduced spin transition from diamagnetic $\mathrm{Fe}^{\mathrm{II}} \mathrm{LS}$ to metastable paramagnetic $\mathrm{Fe}^{\mathrm{II}} \mathrm{HS}$ units (Fig. 3a). When the sample was heated from $2 \mathrm{~K}$ after irradiation, the $\chi \mathrm{T}$ value increased steeply to a sharp maximum of $14.7 \mathrm{~cm}^{3} \mathrm{~mol}^{-1} \mathrm{~K}$ at $4.6 \mathrm{~K}$, which was much larger than the $\chi \mathrm{T}$ value of $4.75 \mathrm{~cm}^{3} \mathrm{~mol}^{-1} \mathrm{~K}$ measured at $300 \mathrm{~K}$. The larger $\chi \mathrm{T}$ value after 

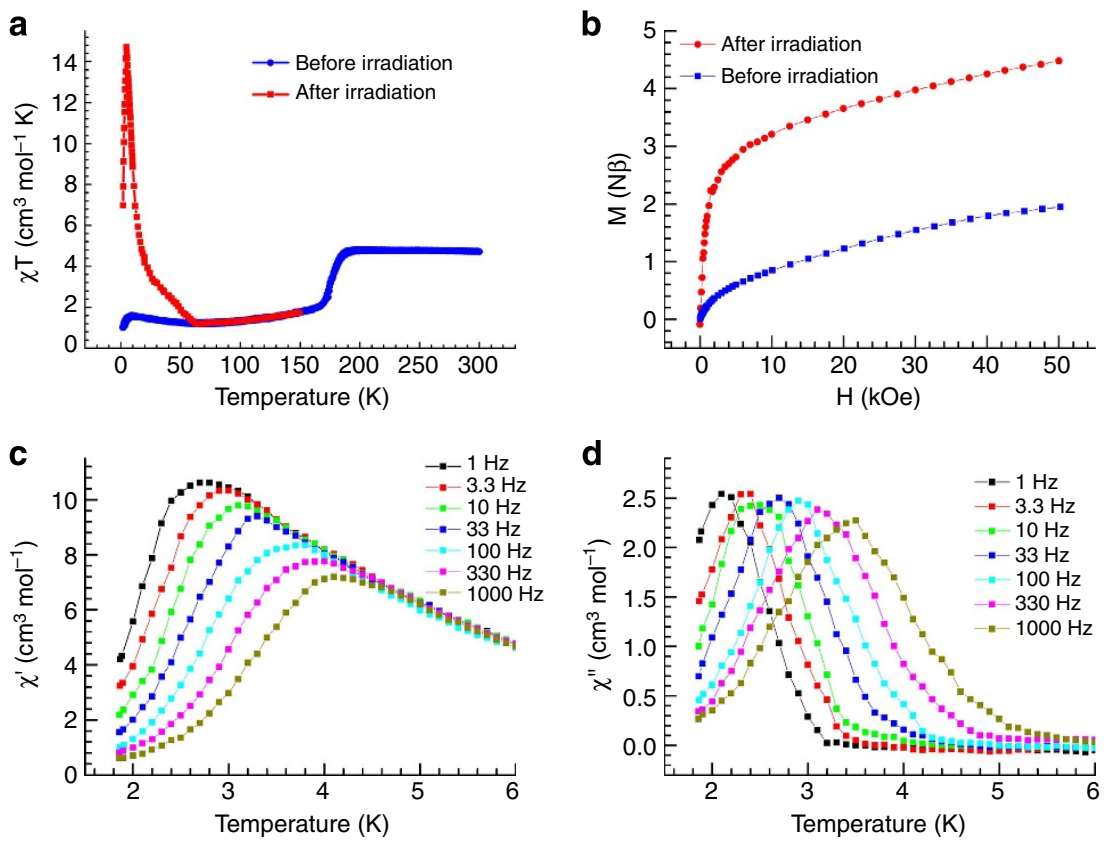

Figure 3 | Magnetic characteristics before and after light irradiation. Alternating current (ac) magnetic susceptibility characteristics after irradiation were performed in a zero dc field at various ac frequencies and with a $3.5 \mathrm{Oe}$ ac field. (a) Temperature dependence susceptibilities of compound $\mathbf{1}$ before (blue squares) and after irradiation (red dots) in a dc field of 1,000 Oe. (b) Isothermal magnetization of compound $\mathbf{1}$ before (blue squares) and after irradiation (red dots) at $1.8 \mathrm{~K}$. (c) Temperature dependence of the real parts of ac magnetic susceptibility after irradiation. (d) Temperature dependence of the imaginary parts of ac magnetic susceptibility after irradiation.

irradiation suggested the presence of a magnetic interaction between the light-induced $\mathrm{Fe}^{\mathrm{II}}{ }_{\mathrm{HS}}(S=2)$ and the $\mathrm{Fe}^{\mathrm{III}}$ LS $(S=1 / 2)$ in the chain. The photoinduced magnetization relaxed to the initial value on a thermal treatment up to $62 \mathrm{~K}$, indicating that the magnetization can be increased by irradiation with light and recovered with a thermal treatment (Supplementary Fig. S3). After light irradiation, the field-dependent magnetization increased steeply below $10 \mathrm{kOe}$ and then linearly to $4.49 \mathrm{~N} \beta$ for up to $50 \mathrm{kOe}$ (Fig. 3b) on increasing the applied magnetic field, suggesting a ferromagnetic behaviour resulting from the ferromagnetic interactions between $\mathrm{Fe}^{\mathrm{III}}$ LS and photoinduced $\mathrm{Fe}^{\mathrm{II}}{ }_{\mathrm{HS}}$ in the $\mathrm{Fe}_{\mathrm{LS}}^{\mathrm{III}} \mathrm{Fe}_{\mathrm{HS}}^{\mathrm{II}} \mathrm{Fe}^{\mathrm{III}}$ LS chain. The magnetization did not reach saturation even at $50 \mathrm{kOe}$, indicating the incomplete photoinduced spin transition and strong anisotropy of photoproduced $\mathrm{Fe}^{\mathrm{II}}{ }_{\mathrm{HS}}$.

To investigate the magnetization dynamics after irradiation, ac magnetic susceptibility was studied as a function of both temperature and frequency. Variable-temperature ac susceptibility measurements revealed a strong frequency dependence of both $\chi^{\prime}$ (Fig. 3c) and $\chi^{\prime \prime}$ (Fig. 3d), as was observed in case of other SCMs. The shift in the peak temperature $\left(T_{\mathrm{p}}\right)$ is given by the parameter $F=\left(\Delta T_{\mathrm{p}} / T_{\mathrm{p}}\right) / \Delta(\log \omega)=0.15$, which lies in the expected range for an SCM, thus eliminating the possibility of a spin-glass behaviour. On the basis of these data, the relaxation times were estimated and fitted to Arrhenius laws (Supplementary Fig. S4), providing a pre-exponential factor of $\tau_{0}=5.0 \times 10^{-10} \mathrm{~s}$ and a relaxation energy barrier of $\Delta_{\tau} / k_{\mathrm{B}}=43.0$ $K$. The value of $\tau_{0}$ provides a quantitative estimation of the attempt time of relaxation from the chain bath and the obtained value is in good agreement with those reported for other $\mathrm{SCMs}^{14-18}$. In addition, harmonic analyses of the ac magnetic susceptibility $(1 \mathrm{~Hz})$ after irradiation (Supplementary Fig. S5) showed that the ac signal does not contain $\chi_{2 \omega}$ and $\chi_{3 \omega}$ nonlinear magnetic susceptibility, suggesting that a single chain is magnetically isolated. A semicircular Cole-Cole diagram $\left(\chi^{\prime \prime}\right.$ versus $\chi^{\prime}$, Supplementary Fig. S6) was constructed from the variable-frequency data collected at $2.5 \mathrm{~K}$ and fit to a generalized
Debye model, yielding an $\alpha$-value of 0.45 . The $\alpha$-value was large, indicating a broad distribution of the relaxation time, which may be due to the presence of defects in the chain, because unconverted LS Fe $\mathrm{Fe}^{\mathrm{II}}$ atoms are present in the chain. This analysis demonstrates that compound $\mathbf{1}$ shows an SCM behaviour after irradiation.

Relaxation of the photoinduced metastable state was monitored at different temperatures to probe the stability of the photoinduced phases (Supplementary Fig. S7) ${ }^{23}$. In the high-temperature range $(30-50 \mathrm{~K})$, the relaxation time $\tau$ was strongly dependent on temperature because of the Arrhenius-type relaxation. In the lowtemperature $(5-10 \mathrm{~K})$ region, relaxation time $\tau$ was less dependent on temperature, suggesting a temperature-independent tunnelling of the system from the metastable $\mathrm{Fe}^{\mathrm{III}}{ }_{\mathrm{LS}} \mathrm{Fe}^{\mathrm{II}}{ }_{\mathrm{HS}} \mathrm{Fe}^{\mathrm{III}}$ LS state to the stable $\mathrm{Fe}^{\mathrm{III}}{ }_{\text {LS }} \mathrm{Fe}^{\mathrm{II}}{ }_{\text {LS }} \mathrm{Fe}^{\mathrm{III}}$ LS state (Supplementary Fig. S8).

\section{Discussion}

Density functional theory (DFT) calculations were carried out to estimate changes in electronic structures (Fig. 4 and Supplementary Table S4). A three-cluster model was used to calculate the spin densities and electronic states of $\mathbf{1}$ (Supplementary Tables S5 and S6). Supplementary Table S4 shows LS ferromagnetic (LSFM) state was the ground state and LS antiferromagnetic state was above $0.09 \mathrm{kcal} \mathrm{mol}^{-1}$. DFT calculations indicate a weak ferromagnetic coupling between two $\mathrm{Fe}^{\mathrm{III}}$ LS ions. In the metastable HS state, HS ferromagnetic (HSFM) state was calculated to be $0.34 \mathrm{kcal} \mathrm{mol}^{-1}$ in the lowlying septet state. HS antiferromagnetic and HS ferro- and antiferromagnetic states were $3.14 \mathrm{kcal} \mathrm{mol}^{-1}$ in the triplet state and $2.16 \mathrm{kcal} \mathrm{mol}^{-1}$ in the quintet state, respectively. Thus, HSFM is also predominant in the metastable HS. These results suggest that a ferromagnetic exchange coupling between $\mathrm{Fe}^{\mathrm{III}}$ LS and $\mathrm{Fe}^{\mathrm{II}}$ HS units causes the predominant magnetic interaction in the double-zigzag chain in compound 1. Calculated spin densities of three metal centres were $\mathrm{Fe}^{\mathrm{III}}{ }_{\mathrm{LS}}(1.07), \mathrm{Fe}_{\mathrm{LS}}^{\mathrm{II}}(0.08)$ and 
a

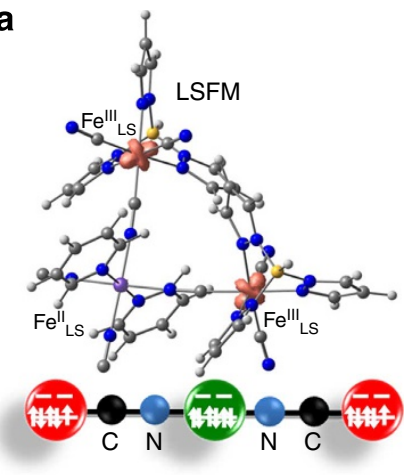

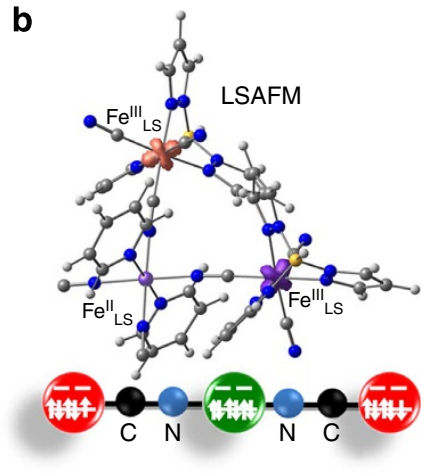

C

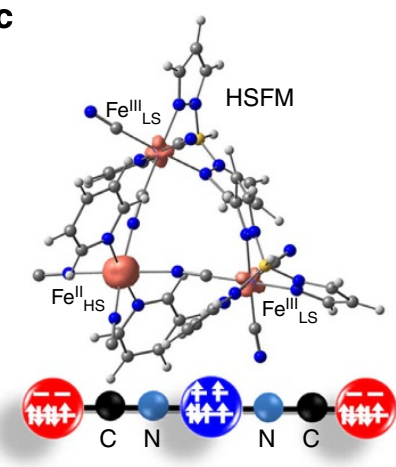

d

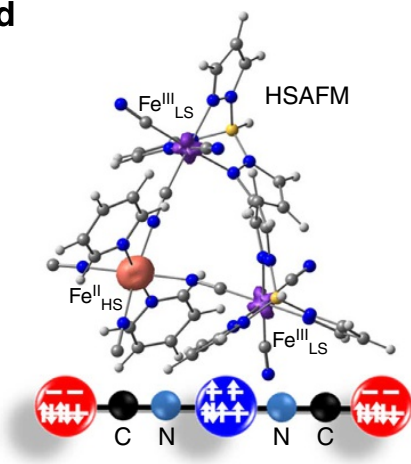

e

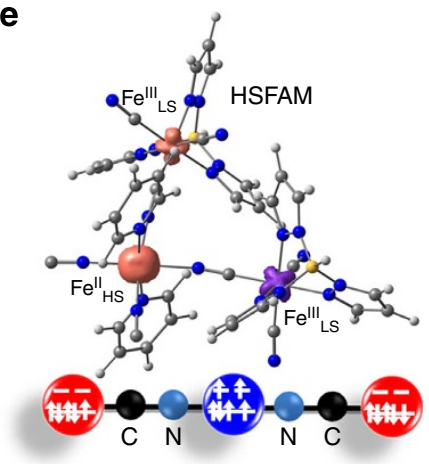

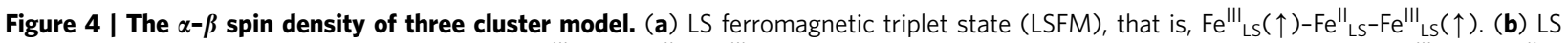

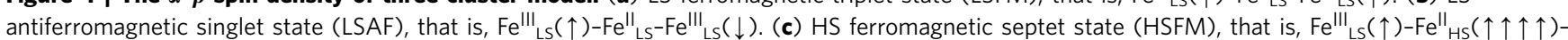

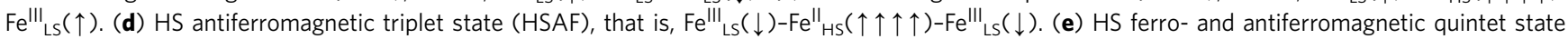
(HSFAM), that is, $\mathrm{Fe}^{\mathrm{III}}{ }_{\mathrm{LS}}(\uparrow)-\mathrm{Fe}^{\prime \prime}{ }_{\mathrm{HS}}(\uparrow \uparrow \uparrow \uparrow)-\mathrm{Fe}^{\mathrm{III}}{ }_{\mathrm{LS}}(\downarrow)$.

$\mathrm{Fe}^{\mathrm{III}}{ }_{\mathrm{LS}}(1.05)$ in the LSFM state, and $\mathrm{Fe}^{\mathrm{III}}{ }_{\mathrm{LS}}$ (1.09), $\mathrm{Fe}^{\mathrm{II}}{ }_{\mathrm{HS}}(3.91)$ and $\mathrm{Fe}^{\mathrm{IIIS}}$ LS $(0.97)$ in the HSFM state (Supplementary Table S4).

Furthermore, to support the occurrence of the LIESST effect, we measured the ultraviolet-visible-near infrared absorption spectra of the high-temperature phase, low-temperature phase and the low-temperature phase after photoirradiation (Supplementary Fig. S9). When the HS state thermally changed to the LS state, the absorption peaks near 550 and $1,100 \mathrm{~nm}$ increased. This change in absorption intensity is induced by a spin transition from $\mathrm{HS}$ to $\mathrm{LS}$ at the $\mathrm{Fe}^{\mathrm{II}}$ sites, which has been confirmed via Mössbauer measurements and single crystal analysis. On the basis of previously reported results for $\mathrm{Fe}^{\mathrm{II}}$ SCO complexes, the broad absorption band near $550 \mathrm{~nm}$ for the low-temperature phase with $\mathrm{Fe}^{\mathrm{II}}$ LS can be mainly attributed to the metal-to-ligand charge transfer (MLCT) transition (Supplementary Fig. S9). Furthermore, the absorption near $1,100 \mathrm{~nm}$ is probably attributable to the intervalence charge transfer from $\mathrm{Fe}_{\text {LS }}^{\mathrm{II}}$ to $\mathrm{Fe}^{\mathrm{III}}{ }_{\mathrm{LS}}$. The photoinduced magnetization was observed when the compound was irradiated with 473 and $532 \mathrm{~nm}$ light; these wavelengths correspond to the excitation of the MLCT transition.

When the LIESST effect is actually induced by light, the hightemperature phase should be generated. Indeed, when the complex with $\mathrm{Fe}_{\text {LS }}^{\mathrm{II}}$ was irradiated at $8 \mathrm{~K}$, the intensity of the peaks near 550 and $1,100 \mathrm{~nm}$ decreased. This result suggests that the low-temperature phase with $\mathrm{Fe}^{\mathrm{II}}$ LS transformed into the hightemperature phase with $\mathrm{Fe}^{\mathrm{II}}{ }_{\mathrm{HS}}$ and is consistent with the occurrence of a spin transition because of light exposure. Notably, the photoinduced change is incomplete, because the interiors of the particles in the complex remain unchanged.

To further confirm that the absorption change induced by light and temperature is consistent with the induction of a spin transition, time-dependent DFT calculations were used to calculate the excited-state energies, oscillator strengths and the electron density difference maps (Supplementary Fig. S10). The time-dependent-DFT calculations show that the strong absorption near $550 \mathrm{~nm}$ is primarily because of the MLCT band. Similarly, the absorption near $1,100 \mathrm{~nm}$ for the low-temperature phase is because of the intervalence charge transfer from $\mathrm{Fe}^{\mathrm{II}}$ LS to $\mathrm{Fe}_{\text {LII }}^{\mathrm{III}}$ Thus, this result supports the conclusion that the thermally and photo-induced absorption changes are because of the spin transition in $\mathrm{Fe}^{\mathrm{II}}$.

In summary, Fe $\mathrm{FI}^{\mathrm{II}} \mathrm{SCO}$ units and paramagnetic $\mathrm{Fe}^{\mathrm{III}}$ ions were alternated successfully in a double-zigzag chain. The SCM behaviour was switched with LIESST because of the formation of a ferromagnetic chain after irradiation. The present results provide an approach to combine the SCO and the SCM behaviour together to control the bistable state of molecular nanomagnets via LIESST effect, with the potential to erase and write information at a molecular level.

\section{Methods}

Synthesis of compound 1. All reagents were available commercially and used without further purification. The compound $\left[\mathrm{Bu}_{4} \mathrm{~N}\right]\left[\mathrm{Fe}\left(\mathrm{Tp}^{*}\right)(\mathrm{CN})_{3}\right]$ was synthesized according to a modified literature method ${ }^{39}$. A $1.0-\mathrm{ml}$ aqueous solution containing $0.05 \mathrm{mmol}$ of $\mathrm{Fe}\left(\mathrm{ClO}_{4}\right)_{2} \cdot 6 \mathrm{H}_{2} \mathrm{O}$ was placed at the bottom of a test tube, and a $2.0-\mathrm{ml}$ methanol solution containing $0.1 \mathrm{mmol}$ of $\left[\mathrm{Bu}_{4} \mathrm{~N}\right]\left[\mathrm{Fe}\left(\mathrm{Tp}^{*}\right)(\mathrm{CN})_{3}\right]$ and $0.1 \mathrm{mmol}$ of bpmh was layered on the solution. Crystallization required several weeks, and crystals were obtained in $65 \%$ yield, based on $\mathrm{Fe}\left(\mathrm{ClO}_{4}\right)_{2} \cdot 6 \mathrm{H}_{2} \mathrm{O}$. The elemental analysis calculations yielded the following values for $\mathrm{C}_{48} \mathrm{H}_{58} \mathrm{~B}_{2} \mathrm{Fe}_{3} \mathrm{~N}_{22} \mathrm{O}_{2}$ : C, 49.52; $\mathrm{H}, 5.02$; and $\mathrm{N}, 26.47$; on the other hand, the corresponding observed values were as follows: $\mathrm{C}, 49.56$; $\mathrm{H}, 4.94$; and $\mathrm{N}, 26.61$.

Mössbauer spectra measurements. Mössbauer spectra (isomer shift versus metallic iron at room temperature) were measured using a Wissel MVT-1000 Mössbauer spectrometer with a ${ }^{57} \mathrm{Co} / \mathrm{Rh}$ source in the transmission mode. Measurements at low temperature were performed using a closed-cycle helium 
refrigerator cryostat (Iwatani Co., Ltd). The sample was encapsulated in a sample holder to avoid loss of crystal water when pulling a vacuum on the cryostat.

Ultraviolet-visible-near infrared spectroscopy. Variable-temperature ultraviolet-visible-near infrared absorption spectra were measured using a UV-3100 (Shimadzu) with a helium-flow type refrigerator (Helitran LT-3-110). We measured the ultraviolet-visible-near infrared absorption spectra of the hightemperature phase, low-temperature phase and the low-temperature phase after photoirradiation.

Thermogravimetric analysis. Thermogravimetric analysis was performed at a rate of $10^{\circ} \mathrm{C} \mathrm{min}^{-1}$ under an Ar atmosphere using a TG/DTA Q600 system (Supplementary Fig. S11).

Magnetic studies. Magnetic measurements of the samples were performed using a Quantum Design SQUID (MPMS-XL-7) magnetometer. On pumping at room temperature, the uncoordinated water molecules of compound $\mathbf{1}$ are removed easily, which may change the magnetic properties significantly. To prevent the loss of these uncoordinated water molecules, measurements were performed on finely ground microcrystalline powders of compound $\mathbf{1}$ restrained in a frozen eicosane matrix with polycarbonate capsules. Data were corrected for the diamagnetic contribution calculated from Pascal constants.

Magnetic studies of the dehydrated samples were performed under a 1,000 Oe field in the temperature range from 2 to $400 \mathrm{~K}$ (Supplementary Fig. S12). The sample was mounted into the SQUID machine and purged at $400 \mathrm{~K}$ to avoid the adsorption of water during the measurement.

Photomagnetic measurements. A powdered sample, which was spread on a commercial transparent adhesive tape, was used to study the photo-effects. The weight of the sample on the tape was determined by measuring the weight of the tape before and after spreading the sample and determining the difference. To prevent the loss of uncoordinated water molecules, the sample was introduced directly into the sample chamber at $100 \mathrm{~K}$ (He atmosphere) without purging.

The photoirradiation of the samples was performed at $5 \mathrm{~K}$ with a laser diode pumped Nd:YAG laser $\left(\lambda=532 \mathrm{~nm}, 30 \mathrm{~mW} \mathrm{~cm}^{-2}, 12 \mathrm{~h}\right)$ or Nd:YAG laser $\left(\lambda=473 \mathrm{~nm}, 20 \mathrm{~mW} \mathrm{~cm}^{-2}, 12 \mathrm{~h}\right)$. The temperature-dependent magnetization was measured both before and after irradiation in the temperature range from 2 to $150 \mathrm{~K}$. The difference in the magnetization before and after irradiation was extracted by subtracting the magnetization value before irradiation from that after irradiation. Furthermore, from these magnetization values and the sample weight, the difference in the $\chi \mathrm{T}$ values before and after irradiation $(\Delta \chi \mathrm{T})$ were calculated.

Structure determinations and refinements. The X-ray diffraction experiment for compound $\mathbf{1}$ was performed on a Rigaku charge-coupled device diffractometer using Mo-K $\alpha$ radiation at 296 and $13 \mathrm{~K}$. The structures were solved by a direct method and refined by full-matrix least-squares on $F^{2}$ using the SHELX programme with anisotropic thermal parameters for all non-hydrogen atoms. Hydrogen atoms were added geometrically and refined using the riding model.

Computational methods. A three-cluster model of compound $\mathbf{1}$ was optimized in the LS triplet state (LSFM) and the HS septet state (HSFM) using the DFT. After optimization, we carried out single-point calculations (for HS and LS) and obtained electronic structures of the LS antiferromagnetic, HS antiferromagnetic and HS ferro- and antiferromagnetic states. The B3LYP* function ${ }^{40}$ was used. The SDD basis set ${ }^{41}$ was used for Fe atom and the D $95^{* *}$ basis set ${ }^{42}$ for $\mathrm{H}, \mathrm{C}, \mathrm{B}$ and $\mathrm{N}$ atoms. The programme we used is Gaussian 09 (ref. 43).

\section{References}

1. Gütlich, P. \& Goodwin, H. A. (eds) Spin Crossover in Transition Metal Compounds I-III (Springer, 2004).

2. Real, J. A. et al. Spin crossover in a catenanesupramolecular system. Science 268, 265-267 (1995).

3. Kahn, O. \& Martinez, C. J. Spin-transition polymers: from molecular materials toward memory devices. Science 279, 44-48 (1998).

4. Halder, G. J., Kepert, C. J., Moubaraki, B., Murray, K. S. \& Cashion, J. D. Guestdependent spin crossover in a nanoporousmolecular framework material. Science 298, 1762-1765 (2002).

5. Bousseksou, A., Molnár, G., Demont, P. \& Menegotto, J. Observation of a thermal hysteresis loop in the dielectric constant of spin crossover complexes: toward molecular memory devices. J. Mater. Chem. 13, 2069-2071 (2003).

6. Prins, F. et al. Room-temperature electrical addressing of a bistable spincrossover molecular system. Adv. Mater. 23, 1545-1549 (2011).

7. Venkataramani, S. et al. Magnetic bistability of molecules in homogeneous solution at room temperature. Science 331, 445-448 (2011).

8. Gatteschi, D., Sessoli, R. \& Villain, J. Molecular Nanomagnets (Oxford Universuty Press, 2006).
9. Sessoli, R., Gatteschi, D., Caneschi, A. \& Novak, M. A. Magnetic bistability in a metal-ion cluster. Nature 365, 141-143 (1993).

10. Mannini, M. et al. Quantum tunneling of the magnetization in a monolayer of oriented single-molecule magnets. Nature 468, 417-421 (2010).

11. Rinehart, J. D., Fang, M., Evans, W. J. \& Long, J. R. Strong exchange and magnetic blocking in $\mathrm{N}_{2}^{3-}$ radical-bridged lanthanide complexes. Nat. Chem. 3, 538-542 (2011).

12. Vincent, R., Klyatskaya, S., Ruben, M., Wernsdorfer, W. \& Balestro, F. Electronic read-out of a single nuclear spin using amolecular spin transistor. Nature 488, 357-359 (2012).

13. Bogani, L. \& Wernsdorfer, W. Molecular spintronics using single-molecule magnets. Nat. Mater. 7, 179-186 (2008).

14. Clérac, R., Miyasaka, H., Yamashita, M. \& Coulon, C. Evidence for single-chain magnet behaviour in a $\mathrm{Mn}^{\mathrm{III}}-\mathrm{Ni}^{\mathrm{II}}$ chain designed with high spin magnetic units: a route to high temperature metastable magnets. J. Am. Chem. Soc. 124, 12837-12844 (2002).

15. Caneschi, A. et al. Cobalt(ii)-nitronyl nitroxide chains as molecular magnetic nanowires. Angew. Chem. Int. Ed. 40, 1760-1763 (2001).

16. Miyasaka, H., Julve, M., Yamashita, M. \& Clérac, R. Slow dynamics of the magnetization in one-dimensional coordination polymers: single-chain magnets. Inorg. Chem. 48, 3420-3427 (2009).

17. Zhang, W. X., Ishikawa, R., Breedlove, B. \& Yamashita, M. Single-chain magnets: beyond the Glauber model. RSC Adv. 3, 3772-3798 (2013).

18. Sun, H. L., Wang, Z. M. \& Gao, S. Strategies towards single-chain magnets. Coord. Chem. Rev. 254, 1081-1100 (2010).

19. Decurtins, S., Gütlich, P., Köhler, C. P., Spiering, H. \& Hauser, A. Ligt-induced excited spin state trapping in a transition-metal complex: the hexa-1propyltetrazole-iron(II) tetrafluoroborate spin-crossover system. Chem. Phys. Lett. 105, 1-4 (1984).

20. Gütlich, P., Hauser, A. \& Spiering, H. Thermal and optical switching of iron(II) complexes. Angew. Chem. Int. Ed. 33, 2024-2054 (1994).

21. Nasu, K. Relaxations of Excited States and Photo-Induced Structural Phase Transitions (Springer, 1997).

22. Létard, J. F. et al. Structural, magnetic, and photomagnetic studies of a mononuclear iron(II) derivative exhibiting an exceptionally abrupt spintransition. Light-induced thermal hysteresis phenomenon. Inorg. Chem. 37, 4432-4441 (1998).

23. Ogawa, Y. et al. Dynamical aspects of the photoinduced phase transition in spincrossover complexes. Phys. Rev. Lett. 84, 3181-3184 (2000).

24. Hayami, S. et al. First observation of light-induced excited spin state trapping for an Iron(III) complex. J. Am. Chem. Soc. 122, 7126-7127 (2000).

25. Létard, J. F. et al. Light induced excited pair spin state in an Iron(II) binuclear spin-crossover compound. J. Am. Chem Soc. 121, 10630-10631 (1999).

26. Breuning, E. et al. Spin crossover in a supramolecular Fe4II [ $2 \times 2]$ grid triggered by temperature, pressure, and light. Angew. Chem. Int. Ed. 39, 2504-2507 (2000).

27. Renz, F. et al. Strong field iron (II) complex converted by light into a long-lived high-spin state. Angew. Chem. Int. Ed. 39, 3699-3700 (2000).

28. Nihei, M. et al. Two-step spin conversion in a cyanide-bridged ferrous square Angew. Chem. Int. Ed. 44, 6484-6487 (2005).

29. Hayami, S., Juhasz, G., Maeda, Y., Yokoyama, T. \& Sato, O. Novel structural and magnetic properties of a 1-D Iron(II) - Manganese(II) LIESST compound bridged by cyanide. Inorg. Chem. 44, 7289-7291 (2005).

30. Ould-Moussa, N. et al. Wavelength selective light-induced magnetic effects in the binuclear spin crossover compound $\left\{\left[\mathrm{Fe}(\mathrm{bt})(\mathrm{NCS})_{2}\right]_{2}(\right.$ bpym $\left.)\right\}$. Phys. Rev. B 75, 054101 (2007).

31. Nishihara, T., Nihei, M., Oshio, H. \& Tanaka, K. The light-induced spin transition of tetranuclear spin crossover complex $\left[\mathrm{Fe}_{4}(\mathrm{CN})_{4}(\mathrm{bpy})_{4}(\mathrm{tpa})_{2}\right]\left(\mathrm{PF}_{6}\right)_{4}$ J. Phys. Confer. Ser. 148, 012033 (2009).

32. Wei, R.-J., Huo, Q., Tao, J., Huang, R.-B. \& Zheng, L.-S. Spin-crossover Fe ${ }_{4}{ }_{4}$ squares: two-step complete spin transition and reversible single-crystal-tosingle-crystal transformation. Angew. Chem. Int. Ed. 50, 8940-8943 (2011).

33. Mondal, A. et al. Photomagnetic effect in a cyanide-bridged mixed-valence $\left\{\mathrm{Fe}_{2}{ }_{2} \mathrm{Fe}^{\mathrm{III}}{ }_{2}\right\}$ molecular square. Chem. Commun. 48, 5653-5655 (2012).

34. Ohkoshi, S., Imoto1, K., Tsunobuchi, Y., Takano, S. \& Tokoro, H. Lightinduced spin-crossover magnet. Nat. Chem. 3, 564-569 (2011).

35. Dong, D.-P. et al. Photoswitchable dynamic magnetic relaxation in a wellisolated $\{\mathrm{Fe} 2 \mathrm{Co}\}$ double-zigzag chain. Angew. Chem. Int. Ed. 51, 5119-5123 (2012).

36. Hoshino, N. et al. Three-way switching in a cyanide-bridged [CoFe] chain. Nat. Chem. 4, 921-926 (2012).

37. Heintze, E. et al. Dynamic control of magnetic nanowires by light-induced domain-wall kickoffs. Nat. Mater. 12, 202-206 (2013).

38. Mitsumoto, K., Ui, M., Nihei, M., Nishikawa, H. \& Oshio, H. Single chain magnet of a cyanide bridged $\mathrm{Fe}^{\mathrm{II}} / \mathrm{Fe}^{\mathrm{III}}$ complex. CrystEngComm 12, 2697-2699 (2010).

39. Li, D. et al. Single-molecule magnets constructed from cyanometalates: $\left\{\left[\mathrm{Tp}^{*} \mathrm{Fe}^{\mathrm{III}}(\mathrm{CN})_{3} \mathrm{M}^{\mathrm{II}}(\mathrm{DMF})_{4}\right]_{2}[\mathrm{OTf}]_{2}\right\} \cdot 2 \mathrm{DMF}\left(\mathrm{M}^{\mathrm{II}}=\mathrm{Co}, \mathrm{Ni}\right)$. Inorg. Chem. 44, 4903-4905 (2005). 
40. Reiher, M., Salomon, O. \& Hess, B. A. Reparameterization of hybridfunctionals based on energy differences of states of different multiplicity. Theor. Chem. Acc. 107, 48-55 (2001).

41. Dolg, M., Wedig, U., Stoll, H. \& Preuss, H. Energy-adjusted ab initio pseudopotentials for the first row transition elements. J. Chem. Phys. 86, 866-872 (1987)

42. Dunning, Jr. T. H. \& Hay, P. J. in Modern Theoretical Chemistry Vol. 3 (Ed. Schaefer, III H. F.) 1-28 (Plenum, New York, 1976)

43. Frisch, M. J. et al. Gaussian 09, Revision C.1 (Gaussian, Inc., Wallingford, CT, 2009).

\section{Acknowledgements}

This work was partly supported by the NSFC (grants 21101021, 91122031 and 21322103), the Fundamental Research Funds for the Central Universities, a KAKEN on Innovative Areas ('Coordination Programming' Area 2107, number 24108731) from MEXT (Japan), the Mitsubishi Foundation, Yazaki Memorial Foundation for Science and Technology and the Network Joint Research Center for Materials and Devices.

\section{Author contributions}

T.L. and C.D. in Dalian and O.S. in Fukuoka conceived and supervised the project. H.Z., S. Kang and S. Kanegawa planned and implemented the synthesis and characterization of materials, and analysed the magnetic measurement data. Y.S. and K.Y. contributed to the DFT calculation. S.H. carried out the Mössbauer measurement. M.M. contributed to harmonic analyses of the ac magnetic susceptibility. T.L. and O.S. wrote the manuscript. All authors discussed the results and commented on the manuscript.

\section{Additional information}

Accession codes: The X-ray crystallographic coordinates for structures reported in this study have been deposited at the Cambridge Crystallographic Data Centre (CCDC), under deposition numbers CCDC-942943 (compound 1 at 296 K) and CCDC-942942 (compound 1 at $13 \mathrm{~K}$ ). These data can be obtained free of charge from The Cambridge Crystallographic Data Centre via www.ccdc.cam.ac.uk/data_request/cif.

Supplementary Information accompanies this paper at http://www.nature.com/ naturecommunications

Competing financial interests: The authors declares no competing financial interests.

Reprints and permission information is available online at http://npg.nature.com/ reprintsandpermissions/

How to cite this article: Liu, T. et al. A light-induced spin crossover actuated singlechain magnet. Nat. Commun. 4:2826 doi: 10.1038/ncomms3826 (2013). 